Bull. Chem. Soc. Ethiop. 2017, 31(1), 149-157.

ISSN 1011-3924

(c) 2017 Chemical Society of Ethiopia and The Authors

Printed in Ethiopia

DOI: http://dx.doi.org/10.4314/bcse.v31i1.13

\title{
RADICAL SCAVENGING ACTIVITY OF SOME NATURAL TROPOLONES BY DENSITY FUNCTIONAL THEORY
}

\author{
Abdullah G. Al-Sehemi ${ }^{1,2}$, Ahmad Irfan ${ }^{1,2^{*}}$, Ahmed al Fahad ${ }^{3}$, Mohammad Alfaifi ${ }^{4}$ \\ ${ }^{1}$ Research Center for Advanced Materials Science (RCAMS), King Khalid University, Abha \\ 61413, P. O. Box 9004, Saudi Arabia \\ ${ }^{2}$ Department of Chemistry, Faculty of Science, King Khalid University, Abha 61413, P. O. Box \\ 9004, Saudi Arabia \\ ${ }^{3}$ Chemistry Department, Faculty of Science, Al Baha University, Al Baha, Saudi Arabia \\ ${ }^{4}$ Department of Biology, Faculty of Science, King Khalid University, Abha 61413, P. O. Box \\ 9004, Saudi Arabia
}

(Received September 1, 2016; revised May 18, 2017)

\begin{abstract}
The ground state neutral geometries of some natural tropolones, i.e. stipitatonic acid (AF1), stipitalide (AF2), stipitaldehydic acid (AF3) and methyl stipitate (AF4) have been optimized by using Density Functional Theory (DFT) at B3LYP/6-31G*, B3LYP/6-31G**, B3LYP/6-31+G* and B3LYP/6-31+G** levels of theory. The excited state geometries of AF1-AF4 were optimized by adopting the Time Dependent Density Functional Theory (TDDFT) at the same levels of theory. The frequencies and cation species of AF1-AF4 were also computed at all the above mentioned levels of theory. We shed light on the electro-optical and molecular properties, e.g. energy gaps, highest occupied molecular orbitals, lowest unoccupied molecular orbitals, absorption wavelengths, electronegativity $(\chi)$, hardness $(\eta)$, electrophilicity $(\omega)$, softness $(S)$, electrophilicity index $(\omega i)$ and the radical scavenging activity (RSA). Hydrogen atom transfer (HAT) and one-electron transfer mechanisms have been discussed to shed light on the RSA. The smallest ionization potential and bond dissociation energy of AF4 are revealing that this compound would have more RSA than those of other counterparts.
\end{abstract}

KEY WORDS: Density Functional Theory, Tropolones, Molecular properties, Bond dissociation enthalpy, Adiabatic ionization potential

\section{INTRODUCTION}

Oxidative stress prompted by reactive oxygen and nitrogen species can cause destruction to nucleic acids, cellular proteins and lipid membranes which ultimately are the sources of cancer and coronary heart disease [1]. Diouf et al. studied the influence of tropolone on the wood degradation and they found weak antioxidative and radical scavenging properties. Moreover, they also showed tropolone can be used as novel environmentally benign preservative systems [2]. Kadoma and co-workers studied the kinetic radical scavenging activity (RSA) of tropolone by induction period method and found very weak antioxidant properties [3]. The tropolone derivatives have also been used in cosmetic and/or topical pharmaceutical compositions as antioxidant compounds which can prevent skin and/or hair from oxidative damage and aging [4].

The number and arrangement of hydroxyl groups are important parameters for radical scavenging capability. Previously, quantum chemical calculations and density functional theory (DFT) were applied to calculate the adiabatic ionization potential (IP), bond dissociation enthalpy (BDE) and other radical scavenging properties of antioxidant systems [5-11]. The antioxidant activity is associated with the structures of the compounds. Leopoldini and coworkers pointed out that hydrogen bonds are important to stabilize the radicals [12]. However, no calculation about the antioxidant activity of the fungal tropolones stipitatonic acid

*Corresponding author. E-mail: irfaahmad@gmail.com 
(AF1), stipitalide (AF2), stipitaldehydic acid (AF3) and methyl stipitate (AF4) has not been reported (Figure 1). The X-ray structures of these compounds were recently been determined [13]. In this work, the structural, electronic and molecular properties were investigated at DFT level. Our aim is to shed light on the RSA behavior and their capacity through quantum chemical calculations of molecular descriptors, i.e. BDE and IP. This study would also help the experimentalists to synthesize new antioxidant tropolones.

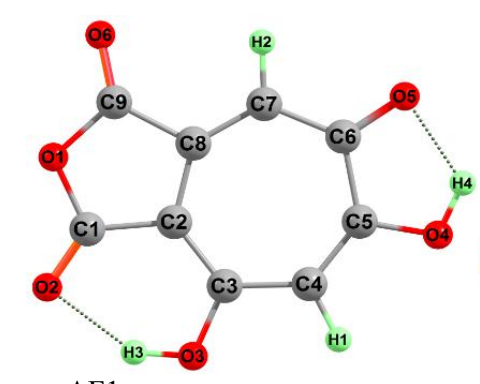

AF1

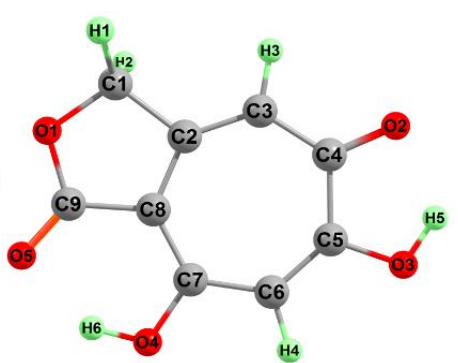

$\mathrm{AF} 2$

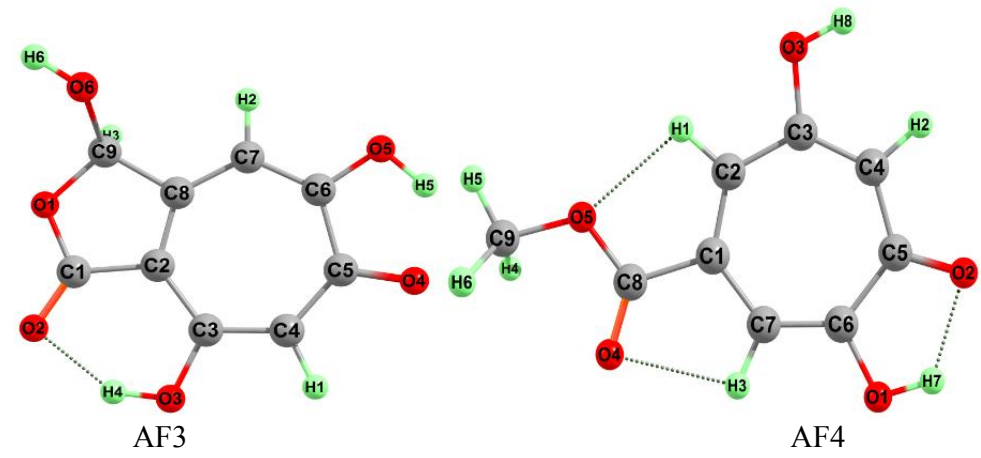

Figure 1. The optimized structures of AF1-AF4 with labeling scheme.

\section{COMPUTATIONAL DETAILS}

Usually H-atom transfer and one-electron transfer mechanisms are used for the radical scavenging processes of chain-breaking antioxidant $(\mathrm{ArOH})[14,15]$. Both the mechanisms are significant for the scavenging activity of reactive species by an $\mathrm{ArOH}$ in biological or chemical system which might happen in parallel.

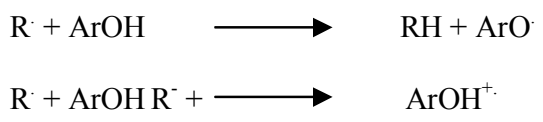

Where Eqs. (1) and (2) represent the H-atom transfer and one-electron transfer mechanisms, respectively. All calculations were performed by using density functional theory (DFT) [16-18] in Gaussian 09 software [19]. Previously, it has been shown that B3LYP is a good and rational functional [20-25]. The B3LYP/6-31G*, B3LYP/6-31G**, B3LYP/6-31+G* and B3LYP/6$31+\mathrm{G}^{* *}$ levels of theory has been applied to optimize the ground state geometries and to calculate the harmonic vibrational frequencies (for both parent (ArOH) systems and radicals 
$\left(\mathrm{ArO}\right.$ and $\left.\mathrm{ArOH}^{+}\right)$. Details can be found in reference [26] and supporting information. The absorption was calculated by time dependent DFT at TD-B3LYP/6-31G* levels of theory which has been found reliable and rational approach [27-30].

\section{RESULTS AND DISCUSSION}

\section{Geometries of the ground and excited states}

The experimental crystal structural geometrical parameters and calculated ones at B3LYP/6$31 \mathrm{G}^{*}, \mathrm{~B} 3 \mathrm{LYP} / 6-31 \mathrm{G}^{* *}, \mathrm{~B} 3 \mathrm{LYP} / 6-31+\mathrm{G}^{*}$ and B3LYP/6-31+G** levels of theory have been tabulated in Tables 1 and $\mathrm{S} 1$. No variations in the bond lengths and bond angles were observed (AF1-AF4) by changing the level of theory which revealed that basis set has no substantial effect on the bond lengths. The experimental bond lengths and bond angles have been reproduced by all the adopted levels of theory see Table 1 . Here the geometrical parameters of $\mathrm{AF} 1-\mathrm{AF} 4$ at B3LYP/6-31+G** level of theory at both the ground and excited states have been compared and discussed. The lengthening/shortening behavior of bond lengths and increase/decrease in the bond angles from the ground to excited states were studied.

Table 1. The bond lengths $(\AA)$ and bond angles $\left({ }^{\circ}\right)$ of stipitatonic acid (AF1), stipitalide (AF2), stipitaldehydic acid (AF3) and methyl stipitate (AF4) calculated at B3LYP/6-31+G**level of theory.

\begin{tabular}{|c|c|c|c|c|c|c|c|}
\hline \multicolumn{2}{|l|}{$\mathrm{AF} 1$} & \multicolumn{2}{|l|}{ AF2 } & \multicolumn{2}{|l|}{$\mathrm{AF} 3$} & \multicolumn{2}{|l|}{$\mathrm{AF} 4$} \\
\hline $\mathrm{C}_{1}-\mathrm{O}_{2}$ & $\begin{array}{l}1.217 \\
(1.189) \\
{[1.232]}\end{array}$ & $\mathrm{C}_{9}-\mathrm{O}_{5}$ & $\begin{array}{l}1.224 \\
(1.219) \\
{[1.229]}\end{array}$ & $\overline{C_{1}-O_{2}}$ & $\begin{array}{l}1.220 \\
(1.216) \\
{[1.239]}\end{array}$ & $C_{1}-C_{8}$ & $\begin{array}{l}1.515 \\
(1.514) \\
{[1.479]}\end{array}$ \\
\hline$\overline{C_{1}-O_{I}}$ & $\begin{array}{l}1.382 \\
(1.398) \\
{[1.335]}\end{array}$ & $C_{9}-O_{l}$ & $\begin{array}{l}1.356 \\
(1.341) \\
{[1.366]}\end{array}$ & $\overline{C_{1}-O_{1}}$ & $\begin{array}{l}1.359 \\
(1.348) \\
{[1.366]}\end{array}$ & $\mathrm{C}_{8}-\mathrm{O}_{4}$ & $\begin{array}{l}1.216 \\
(1.204) \\
{[1.227]}\end{array}$ \\
\hline $\mathrm{C}_{9-O_{1}}$ & $\begin{array}{l}1.398 \\
(1.381) \\
{[1.464]}\end{array}$ & $C_{1}-O_{1}$ & $\begin{array}{l}1.443 \\
(1.457) \\
{[1.436]}\end{array}$ & $\overline{C_{9}-O_{1}}$ & $\begin{array}{l}1.447 \\
(1.470) \\
{[1.454]}\end{array}$ & $\mathrm{C}_{8}-\mathrm{O}_{5}$ & $\begin{array}{l}1.347 \\
(1.334) \\
{[1.361]}\end{array}$ \\
\hline $\mathrm{C}_{9}-\mathrm{O}_{6}$ & $\begin{array}{l}1.196 \\
(1.205) \\
{[1.213]}\end{array}$ & $C_{l}-H_{l}$ & $\begin{array}{l}1.094 \\
(0.990) \\
{[1.096]}\end{array}$ & $\mathrm{C}_{9}-\mathrm{O}_{6}$ & $\begin{array}{l}1.389 \\
(1.362) \\
{[1.399]}\end{array}$ & $\mathrm{C}_{9}-\mathrm{O}_{5}$ & $\begin{array}{l}1.442 \\
(1.440) \\
{[1.438]}\end{array}$ \\
\hline $\mathrm{C}_{6}-\mathrm{O}_{5}$ & $\begin{array}{l}1.245 \\
(1.243) \\
{[1.255]}\end{array}$ & $\mathrm{C}_{4}-\mathrm{O}_{2}$ & $\begin{array}{l}1.250 \\
(1.240) \\
{[1.273]}\end{array}$ & $\mathrm{C}_{5}-\mathrm{O}_{4}$ & $\begin{array}{l}1.254 \\
(1.255) \\
{[1.287]}\end{array}$ & $\mathrm{C}_{5}-\mathrm{O}_{2}$ & $\begin{array}{l}1.253 \\
(1.279) \\
{[1.290]}\end{array}$ \\
\hline$O_{1}-C_{1}-O_{2}$ & $\begin{array}{l}122.32 \\
(121.66) \\
{[125.16]}\end{array}$ & $O_{1}-C_{9}-O_{5}$ & $\begin{array}{l}122.86 \\
(1.240) \\
{[122.44]}\end{array}$ & $O_{1}-C_{1}-O_{2}$ & $\begin{array}{l}122.77 \\
(122.07) \\
{[123.21]}\end{array}$ & $C_{1}-C_{8}-O_{4}$ & $\begin{array}{l}123.71 \\
(123.69) \\
{[124.88]}\end{array}$ \\
\hline$C_{l}-O_{1}-C_{9}$ & $\begin{array}{l}109.15 \\
(108.49) \\
{[110.03]}\end{array}$ & $C_{9}-O_{1}-C_{l}$ & $\begin{array}{l}109.65 \\
(109.21) \\
{[108.98]}\end{array}$ & $C_{1}-O_{1}-C_{9}$ & $\begin{array}{l}109.59 \\
(109.23) \\
{[110.00]}\end{array}$ & $\mathrm{C}_{1}-\mathrm{C}_{8}-\mathrm{O}_{5}$ & $\begin{array}{l}113.23 \\
(112.93) \\
{[112.60]}\end{array}$ \\
\hline$O_{1}-C_{9}-O_{6}$ & $\begin{array}{l}122.20 \\
(121.11) \\
{[120.66]}\end{array}$ & & & $\mathrm{O}_{1}-\mathrm{C}_{9}-\mathrm{O}_{6}$ & $\begin{array}{l}111.29 \\
(110.59) \\
{[110.89]}\end{array}$ & $\mathrm{O}_{4}-\mathrm{C}_{8}-\mathrm{O}_{5}$ & $\begin{array}{l}123.06 \\
(123.38) \\
{[122.52]}\end{array}$ \\
\hline
\end{tabular}

Values in parentheses "()" are experimental data while in brackets "[]" are excited states geometrical parameters.

In $\mathrm{AF} 1, \mathrm{C}_{1}-\mathrm{O}_{1}$ bond length shortened $0.047 \AA$ while $\mathrm{C}_{9}-\mathrm{O}_{1}$ lengthened $0.066 \AA$, from ground to excited state. The $\mathrm{O}_{1}-\mathrm{C}_{1}-\mathrm{O}_{2}$ bond angle increased $2.84^{\circ}$ from ground to excited state. In $\mathrm{AF} 2$ and $\mathrm{AF} 3, \mathrm{C}_{4}-\mathrm{O}_{2}$ and $\mathrm{C}_{5}-\mathrm{O}_{4}$ bond lengths lengthened 0.023 and $0.033 \AA$ from ground to excited state, respectively. In AF4, $\mathrm{C}_{1}-\mathrm{C}_{8}$ bond length shortened $0.036 \AA$ while $\mathrm{C}_{5}-\mathrm{O}_{2}$ lengthened 0.040 
$\AA$ from ground to excited state. At the ground state, significant alterations have been noticed for $\mathrm{C}_{1}-\mathrm{O}_{1}, \mathrm{C}_{9}-\mathrm{O}_{1}$, and $\mathrm{C}_{9}-\mathrm{O}_{6}$ from one compound to other. The $\mathrm{C}_{9}-\mathrm{O}_{1}$ and $\mathrm{C}_{1}-\mathrm{O}_{1}$ bond lengths shortened in $A F 2$ and $A F 3$, i.e., 0.026 and $0.023 \AA$, respectively compared to the $\mathrm{C}_{1}-\mathrm{O}_{1}$ of $\mathrm{AF} 1$. The $\mathrm{C}_{1}-\mathrm{O}_{1}$ and $\mathrm{C}_{9}-\mathrm{O}_{1}$ bond lengths lengthened in $\mathrm{AF} 2$ and $\mathrm{AF} 3$, i.e. 0.045 and $0.045 \AA$, respectively, compared to the $\mathrm{C}_{9}-\mathrm{O}_{1}$ of $\mathrm{AF} 1$. The $\mathrm{C}_{9}-\mathrm{O}_{6}$ bond length of $\mathrm{AF} 3$ lengthened $0.193 \AA$ compared to the AF1.

\section{Molecular properties}

Figure 2 illustrates the distribution pattern of the frontier molecular orbitals (FMOs), i.e. highest occupied molecular orbitals (HOMOs) and lowest unoccupied molecular orbitals (LUMOs). In $\mathrm{AF} 1-\mathrm{AF} 3$, the HOMOs charge density is distributed on the tropone ring and lone pairs of electron on the oxygen atoms. The LUMOs of the AF1-AF3 are of anti-bonding character with $\pi^{*}$ distributed on entire core of the compounds and lone pairs of the electrons on the oxygen atoms. In AF4, HOMO is distributed on tropone ring and its oxygen atoms while LUMO is localized on ring and oxygen atoms of the keto and methoxy. The intra-molecular charge transfer has been observed from tropone ring to the adjacent moiety.

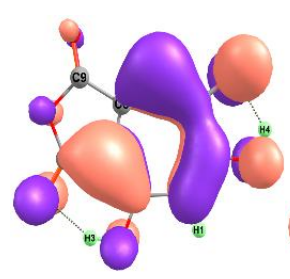

AF 1

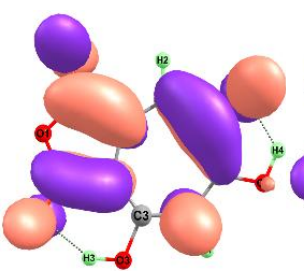

1

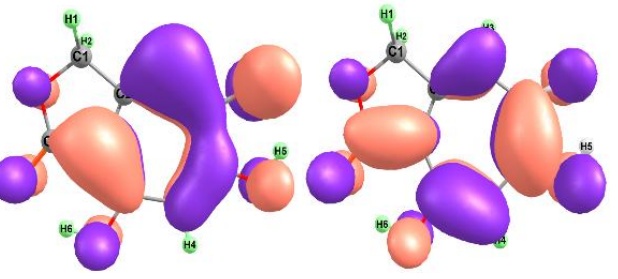

AF2

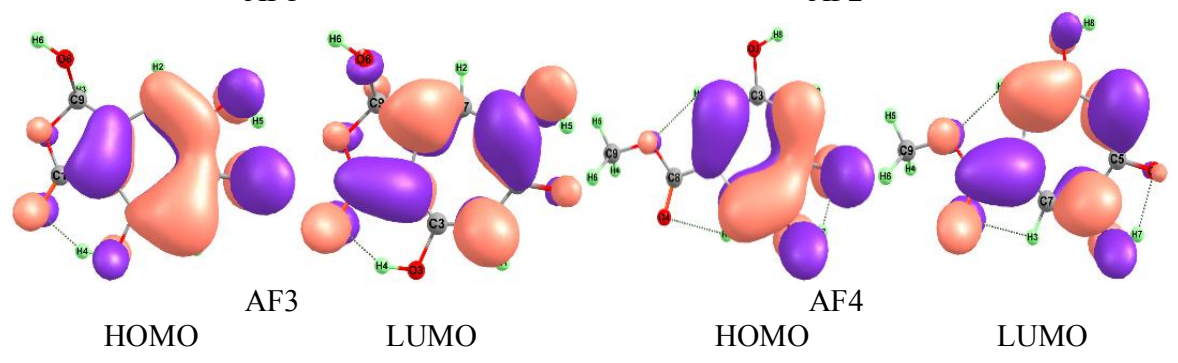

Figure 2. The distribution pattern of the HOMOs and LUMOs of the studied compounds at ground states.

The HOMOs, LUMOs, energy gap, electronegativity $(\chi)$, hardness $(\eta)$, electrophilicity $(\omega)$, softness $(\mathrm{S})$ and electrophilicity index $(\omega \mathrm{i})$ at the B3LYP/6-31G*, B3LYP/6-31G**, B3LYP/6$31+\mathrm{G}^{*}$ and $\mathrm{B} 3 \mathrm{LYP} / 6-31+\mathrm{G}^{* *}$ levels of theory have been presented in Table 2. The HOMO energy $\left(\mathrm{E}_{\text {Hомо }}\right)$, LUMO energy $\left(\mathrm{E}_{\mathrm{LUMO}}\right)$ and HOMO-LUMO energy gap $\left(\mathrm{E}_{\text {gap }}\right)$ has been used as an indicator of kinetic stability of the molecule. It has been observed that the trend of the HOMOs, LUMOs, energy gap, electronegativity $(\chi)$, hardness $(\eta)$, electrophilicity $(\omega)$, softness (S) and electrophilicity index ( $\omega$ i) at all the level of theories is similar. The trend of the HOMO and $\mathrm{LUMO}$ energies is AF4 $>\mathrm{AF} 2>\mathrm{AF} 3>\mathrm{AF} 1$ and energy gaps is AF2 $>\mathrm{AF} 3>\mathrm{AF} 4>\mathrm{AF} 1$. The $\mathrm{E}_{\mathrm{HOMO}}, \mathrm{E}_{\mathrm{LUMO}}$ and $\mathrm{E}_{\text {gap }}$ of $\mathrm{AF} 1-\mathrm{AF} 4$ are lower and smaller than the phenol. The $\chi, \omega, \mathrm{S}$ and $\omega \mathrm{i}$ are larger for the AF1-AF4 than the phenol. The trend of $\chi$ and $\omega$ are AF1 $>$ AF3 $>$ AF2 $>$ AF4 
while $\omega \mathrm{i}$ is $\mathrm{AF} 4>\mathrm{AF} 3>\mathrm{AF} 1>\mathrm{AF} 2$. The values of the $\mathrm{S}$ of all the studied compounds are almost same.

The RSA of antioxidant compounds is interrelated to the delocalization of HOMOs. The lower HOMO energy value revealed that the compound has weaker electron donating ability, i.e. AF1 has lower electron donor ability compared to AF2-AF3. Additionally, from the distribution pattern of the HOMOs the feasible sites (attacked by free radicals and other reactive agents) in the compounds can be predicted. The measure of resistance to charge transfer is known as chemical hardness. The electronegativity is a measure of the tendency to attract electrons by an atom in a chemical bond. The electrophilicity index $(\omega)$ symbolizes the stabilization energy of the compound and determines the affinity for the electrons. The computed molecular properties have been given in Tables 2 which clearly indicates that AF1 is capable of attracting an electron instead of giving them while AF2-AF4 would be proficient as giving electron rather than capturing revealing that these compounds might have higher antioxidant ability than AF1.

Table 2. Different descriptors of AF1-AF4 obtained at B3LYP/6-31+G** levels of theory.

\begin{tabular}{|l|l|l|l|l|}
\hline Parameters & $A F 1$ & $A F 2$ & $A F 3$ & $A F 4$ \\
\hline $\mathrm{E}_{\text {HOMO }}$ & -7.44 & -6.94 & -7.04 & -6.66 \\
\hline $\mathrm{E}_{\text {LUMO }}$ & -3.73 & -2.90 & -3.17 & -2.85 \\
\hline $\mathrm{E}_{\text {gap }}$ & 3.71 & 2.04 & 3.87 & 3.86 \\
\hline$\chi$ & 5.58 & 4.92 & 5.10 & 4.75 \\
\hline$\eta$ & 1.85 & 2.02 & 1.93 & 1.90 \\
\hline$\omega$ & 8.41 & 5.99 & 6.73 & 5.93 \\
\hline $\mathrm{S}$ & 0.27 & 0.25 & 0.26 & 0.26 \\
\hline$\omega \mathrm{i}$ & 2.09 & 0.86 & 5.28 & 5.58 \\
\hline$\mu$ & 2.79 & 1.87 & 4.52 & 4.61 \\
\hline
\end{tabular}

Absorption spectra

The absorption wavelengths, oscillator strengths and transition contribution of tropolone derivatives AF1-AF4 have been computed at TD-B3LYP/6-31G* level of theory and tabulated in Table 3. Two absorption peaks have been observed for AF1, AF2 and AF4 while three for AF3. The maximum absorption wavelength of AF2 is $18 \mathrm{~nm}$ blue shifted while no significant red or blue shift has been observed for AF3 and AF4 as compared to AF1. The contribution of frontier molecular orbitals in the major transitions, i.e. HOMO (H), LUMO (L), HOMO-1 (H1), HOMO-2 (H-2), LUMO (L), LUMO+1 (L+1) have been discussed here. In AF1, the maximum absorption wavelength is caused by $\mathrm{H}-2 \rightarrow \mathrm{L}$ with $56 \%$ contribution while in AF2AF4 aforementioned peak is caused by $\mathrm{H}-1 \rightarrow \mathrm{L}+1$ with 47,56 and $56 \%$ contribution, respectively. The first peak in all the studied tropolone derivatives AF1-AF4 is caused by $\mathrm{H} \rightarrow$ $\mathrm{L}$ with $65,66,67$ and $69 \%$ contribution, respectively. The first peak of AF2 is $30 \mathrm{~nm}$ blue shifted compared to AF1 while AF3 and AF4 have almost the same absorption wavelength alike AF1. An additional peak has been observed in AF3 at $264 \mathrm{~nm}$ from $\mathrm{H} \rightarrow \mathrm{L}+1$ (49\%).

\section{Hydrogen atom transfer mechanism}

By hydrogen abstraction, radicals were obtained in which the hydrogen atoms have been abstracted from hydroxyl group. Single radical cation for each parent molecule was obtained as $\mathrm{AF} 1, \mathrm{AF} 2$ and AF4, two for each while three for AF3. We have presented the BDE values in Table 4 that describe the hydrogen atom donating ability. The BDE values have been compared with each other. The imperative position for hydrogen atom transfer (HAT) is hydroxyl. It can be seen that the BDE values computed at B3LYP/6-31G*, B3LYP/6-31G**, B3LYP/6-31+G* 
and B3LYP/6-31+G** levels of theory showed similar tendency, see Tables 4 and S4. In AF1, the abstraction of hydrogen (H4) would be more favorable to increase the antioxidant properties than the abstraction of H3. In AF2, the abstraction of hydrogen (H5) would be more favorable to increase the antioxidant properties than the abstraction of H6. In AF3, the abstraction of hydrogen (H5) would be more favorable to increase the antioxidant properties than the abstraction of $\mathrm{H} 6$ and $\mathrm{H} 4$. In AF4, the abstraction of hydrogen (H8) would be more favorable to increase the antioxidant properties than the abstraction of $\mathrm{H} 7$. Moreover, small effect has been observed on BDE values by changing the basis set. Here we have discussed and compared the $\mathrm{BDE}$ values at B3LYP/6-31+G** level of theory. The smallest BDE has been observed for the AF4 (BDE, 81.37 by abstraction of H8) followed by AF3 (BDE, 84.65 by abstraction of H6) $\mathrm{Kcal} / \mathrm{mol}$ revealed that these compounds would have more antioxidant ability than those of the other counterparts. Finally, HAT mechanism would be favorable in the AF4 and AF3.

Table 3. Calculated absorption wavelengths $\left(\lambda_{\mathrm{a}}, \mathrm{nm}\right)$, oscillator strengths $(f)$ and transitions of tropolones at B3LYP/6-31G* level of theory.

\begin{tabular}{|c|c|c|l|}
\hline Complexes & $f$ & $\lambda_{\mathrm{a}}$ & Transition \\
\hline AF1 & 0.1057 & 356 & $\mathrm{H} \rightarrow \mathrm{L}(65 \%)$ \\
& 0.2605 & 243 & $\mathrm{H}-2 \rightarrow \mathrm{L}(56 \%)$ \\
\hline AF2 & 0.1285 & 326 & $\mathrm{H} \rightarrow \mathrm{L}(66 \%)$ \\
& 0.6382 & 225 & $\mathrm{H}-1 \rightarrow \mathrm{L}+1(47 \%)$ \\
\hline AF3 & 0.0551 & 354 & $\mathrm{H} \rightarrow \mathrm{L}(67 \%)$ \\
& 0.2851 & 264 & $\mathrm{H} \rightarrow \mathrm{L}+1(49 \%)$ \\
& 0.4899 & 228 & $\mathrm{H}-1 \rightarrow \mathrm{L}+1(56 \%)$ \\
\hline AF4 & 0.0871 & 354 & $\mathrm{H} \rightarrow \mathrm{L}(69 \%)$ \\
& 0.3704 & 231 & $\mathrm{H}-1 \rightarrow \mathrm{L}+1(56 \%)$ \\
\hline
\end{tabular}

Table 4. The BDE and IP of AF1-AF4 at B3LYP/6-31+G** levels of theory $(\mathrm{kcal} / \mathrm{mol})$.

\begin{tabular}{|l|l|l|l|l|}
\hline Compounds & $A F 1$ & $A F 2$ & $A F 3$ & $A F 4$ \\
\hline BDE & $88.86^{\mathrm{a}}$ & $86.73^{\mathrm{c}}$ & $91.30^{\mathrm{e}}$ & $82.26^{\mathrm{h}}$ \\
& $(87.32)^{\mathrm{b}}$ & $(89.46)^{\mathrm{d}}$ & $(84.65)^{\mathrm{f}}$ & $(81.37)^{\mathrm{i}}$ \\
& & & $(92.24)^{\mathrm{g}}$ & \\
\hline IP & 208.21 & 197.00 & 199.20 & 192.04 \\
\hline
\end{tabular}

${ }^{a} \mathrm{BDE}$ ofAF1 by dissociation of $\mathrm{H} 3$; ${ }^{\mathrm{b}} \mathrm{BDE}$ ofAF1 by dissociation of $\mathrm{H} 4$; ${ }^{\mathrm{C}} \mathrm{BDE}$ ofAF2 by dissociation of $\mathrm{H} 5$; ${ }^{\mathrm{d}} \mathrm{BDE}$ ofAF2 by dissociation of $\mathrm{H} 6$; ${ }^{\mathrm{B} D E}$ ofAF3 by dissociation of $\mathrm{H} 4$; ${ }^{\mathrm{f}} \mathrm{BDE}$ ofAF3 by dissociation of $\mathrm{H} 5$; ${ }^{\mathrm{f}} \mathrm{BDE}$ ofAF3 by dissociation of $\mathrm{H} 6$; ${ }^{\mathrm{h}} \mathrm{BDE}$ ofAF4 by dissociation of $\mathrm{H7}$; ${ }^{\mathrm{i}} \mathrm{BDE}$ ofAF4 by dissociation of $\mathrm{H} 8$.

\section{Single electron transfer mechanism}

The scavenging of free radicals may be achieved by donating single electron. The IP is an important physical factor revealing the range of electron transfer. According to the one-electron transfer, an electron is removed from the HOMO of the parent molecules, giving rise to radical cations. The investigated compounds have planer radical cations revealing there would be entire conjugation. The calculated IP values at B3LYP/6-31G* and B3LYP/6-31G** levels of theory are alike. Similarly, the computed values at B3LYP/6-31+G* and B3LYP/6-31+G** levels of theory are comparable. But the tendency in all the four studied compounds (AF1-AF4) is same as $\mathrm{AF} 4<\mathrm{AF} 2<\mathrm{AF} 3<\mathrm{AF} 1$ revealing that in $\mathrm{AF} 4$ electron transfer mechanism would be more favorable for the scavenging of free radicals compared to other counterparts. Moreover, the smaller IP value of AF4 compared to AF1-AF3 revealed that prior would be better antioxidant material (Table 4). 


\section{CONCLUSION}

The charge density of HOMOs is distributed on the tropone ring while LUMOs on entire molecules and lone pair of electrons on the oxygen atoms. The intra-molecular charge transfer has been observed from tropone ring to the adjacent moiety. The AF1 is capable of attracting an electron instead of giving them while AF4 would be proficient to give electron rather than capturing which in turn an indication of their antioxidant ability. The smallest BDE and IP values have been observed for the AF4 illuminating that it would be proficient antioxidant material compared to other counterparts (AF1-AF3).

\section{ACKNOWLEDGEMENT}

The authors would like to express their gratitude to Research Centre of Advanced Materials Science (RCAMS) - King Khalid University, Saudi Arabia for support.

\section{REFERENCES}

1. Pietta, P.-G. Flavonoids as antioxidants. J. Nat. Prod. 2000, 63, 1035-1042.

2. Diouf, N.D.P.N.; Perrin, D.; Gérardin, P.; Rapin, C.; Jacquot, J.P.; Gelhaye, E. Influence of tropolone on Poria placenta wood degradation. Appl. Environ. Microbiol. 2002, 68, 43774382.

3. Kadoma, I.M.; Yokoe, I.; Fujisawa, S. Kinetic radical-scavenging activity of colchicine and tropolone. In Vivo. 2007, 21, 481-486.

4. Schmaus, G.; Franke, H.; Pillai, R. Use of tropolone derivatives as antioxidants in cosmetic and/or topical pharmaceutical compositions. Patent, WO 2008003529 A1; in W.A. Patent (Ed.); 2008.

5. Antonczak, S. Electronic description of four flavonoids revisited by DFT method. J. Mol. Struct.(TheoChem) 2008, 856, 38-45.

6. Kalita, D.; Ka, R.; Handique, J.G. A theoretical study on the antioxidant property of gallic acid and its derivatives. J. Theor. Comput. Chem. 2012, 11, 391-402.

7. Sadasivam, K.; Jayaprakasam, R.; Kumaresan, R. A DFT study on the role of different $\mathrm{OH}$ groups in the radical scavenging process. J. Theor. Comput. Chem. 2012, 11, 871-893.

8. Al-Sehemi, A.G.; Irfan, A.; Aljubiri, S.M.; Shaker, K.H. Combined experimental and computational study of the radical scavenging activity of luteolin. J. Theor. Comput. Chem. 2013, 12, 1350021-1350030.

9. Najafi, M.; Najafi, H. Theoretical study of the substituent effects on the reaction enthalpies of the antioxidant mechanisms of Stobadine derivatives in the gas-phase and water. J. Theor. Comput. Chem. 2013, 12, 1250116-1250134.

10. Mikulski, D.; Eder,K.; Molski, M. Quantum-chemical study on relationship between structure and antioxidant properties of hepatoprotective compounds occurring in Cynarascolymus and Silybummarianum. J. Theor. Comput. Chem. 2014, 13, 14500041450027.

11. Najafi, M.; Naqvi, S.A.R. Theoretical study of the substituent effect on the hydrogen atom transfer mechanism of the irigenin derivatives antioxidant action. J. Theor. Comput. Chem. 2014, 13, 1450010-1450021.

12. Leopoldini, M.; Pitarch, I.P. Russo,N.; Toscano, M. Structure, conformation, and electronic properties of apigenin, luteolin, and taxifolin antioxidants: A first principle theoretical study. J. Phys. Chem. A 2004, 108, 92-96.

13. al Fahad, A.; Abood, A.; Simpson, T.J.; Cox, R.J. The biosynthesis and catabolism of the maleic anhydride moiety of stipitatonic acid. Angew. Chem. Int. Ed. 2014, 53, 7519-7523. 
14. Belcastro, M.; Marino, T.; Russo, N.; Toscano, M. Structural and electronic characterization of antioxidants from marine organisms. Theor. Chem. Acc. 2006, 115, 361-369.

15. Wright, J.S.; Johnson,E.R.; DiLabio, G.A. Predicting the activity of phenolic antioxidants: Theoretical method, analysis of substituent effects, and application to major families of antioxidants. J. Am. Chem. Soc. 2001, 123, 1173-1183.

16. Irfan, A.; Al-Sehemi, A.G. Energy decomposition analysis of " $\mathrm{H} / \mathrm{OH}$ " derivatives of the meridianal isomer of tris(8-hydroxyquinolinato)aluminum (mer-Alq3). J. Chem. Soc. Pak. 2012, 34, 350-354.

17. Al-Sehemi, A.G.; Al-Amri, R.S.A.-A.; Irfan, A. Synthesis, characterization and density functional theory study of di-acylation of $\mathrm{N}$-aminoquinazolin- $4(3 \mathrm{H})$-one derivatives. $J$. Chem. Soc. Pak. 2013, 35, 815-822.

18. Al-Sehemi, A.G.; Ammar,Y.A.; Bondock, S. Synthesis, characterization and DFT study of pyrazole-carboxamides compounds. J. Chem. Soc. Pak. 2014, 36, 96-105.

19. Frisch, M.J.; Trucks, G.W.; Schlegel, H.B.; Scuseria, G.E.; Robb, M.A.; Cheeseman, J.R.; Scalmani, G.; Barone, V.; Petersson, G.A.; Nakatsuji, H.; Li, X.; Caricato, M.; Marenich, A.V.; Bloino, J.; Janesko, B.G.; Gomperts, R.; Mennucci, B.; Hratchian, H.P.; Ortiz, J.V.; Izmaylov, A.F.; Sonnenberg, J.L.; Williams-Young, D.; Ding, F.; Lipparini, F.; Egidi, F.; Goings, J.; Peng, B.; Petrone, A.; Henderson, T.; Ranasinghe, D.; Zakrzewski, V.G.; Gao, J.; Rega, N.; Zheng, G.; Liang, W.; Hada, M.; Ehara, M.; Toyota, K.; Fukuda, R.; Hasegawa, J.; Ishida, M.; Nakajima, T.; Honda, Y.; Kitao, O.; Nakai, H.; Vreven, T.; Throssell, K.; Montgomery, J.A., Jr.; Peralta, J.E.; Ogliaro, F.; Bearpark, M.J.; Heyd, J.J.; Brothers, E. N.; Kudin, K.N.; Staroverov, V.N.; Keith, T.A.; Kobayashi, R.; Normand, J.; Raghavachari, K.; Rendell, A.P.; Burant, J.C.; Iyengar, S.S.; Tomasi, J.; Cossi, M.; Millam, J.M.; Klene, M.; Adamo, C.; Cammi, R.; Ochterski, J.W.; Martin, R.L.; Morokuma, K.; Farkas, O.; Foresman, J.B.; Fox, D.J. Gaussian 09, Revision D.01, Gaussian, Inc.: Wallingford CT; 2009.

20. Irfan, A.; Muhammad, S.; Al-Sehemi, A.G.; Al-Assiri, M.S.; Kalam, A.; Chaudhry, A.R. The effect of anchoring groups on the electro-optical and charge injection in triphenylamine derivatives@ $\mathrm{Ti}_{6} \mathrm{O}_{12}$.J. Theor. Comput.Chem. 2015, 14, 1550027-1550039.

21. Irfan, A.; Muhammad, S.; Al-Sehemi, A.G.; Al-Assiri, M.S.; Kalam, A. Structure modification to tune the electronic and charge transport properties of solar cell materials: Quantum chemical study. Int. J. Electrochem. Sci. 2015, 10, 3600-3612.

22. Irfan, A.; Al-Sehemi, A.G.; Muhammad, S.; Kalam, A.; Chaudhry, A.R.; Shkir, M.; AlSalami, A.; Asiri, A.M. The electro-optical and charge transport study of imidazolidin derivative: Quantum chemical investigations. J. Saudi. Chem. Soc. 2016, 20, 680-685.

23. Irfan, A.; Al-Sehemi, A.G.; Muhammad, S.;Chaudhry, A.R.; Al-Assiri, M.S.; Jin, R.; Kalam, A.; Shkir, M.; Asiri, A.M. In-depth quantum chemical investigation of electrooptical and charge-transport properties of trans-3-(3,4-dimethoxyphenyl)-2-(4-nitrophenyl) prop-2-enenitrile. C R Chim. 2015, 18, 1289-1296.

24. Irfan, A.; Al-Sehemi, A.G.; Muhammad, S.; Al-Assiri, M.S.; Chaudhry, A.R.; Kalam, A.; Shkir, M. Electro-optical and charge injection investigations of the donor- $\pi$-acceptor triphenylamine, oligocene-thiophene-pyrimidine and cyanoacetic acid based multifunctional dyes. J. King Saud Univer.-Sci. 2015, 27, 361-368.

25. Irfan, A. Influence of the substitution on the electronic properties of perylene-3,4:9,10bis(dicarboximides): Density functional theory study. Bull. Chem. Soc. Ethiop. 2014, 28, 101-110.

26. Al-Sehemi, A.G.; Irfan, A.; Aljubiri, S.M.; Shaker, K.H. Density functional theory investigations of radical scavenging activity of 3'-Methyl-quercetin. J. Saudi Chem. Soc. 2016, 20, S21-S28. 
27. Irfan, A.; Kalam, A.; Chaudhry, A.R.; Al-Sehemi,A.G.; Muhammad, S .Electro-optical, nonlinear and charge transfer properties of naphthalene based compounds: A dual approach study. Optik 2017, 132, 101-110.

28. Al-Sehemi, A.G.; Irfan, A.; Asiri, A.M.; Ammar Y.A. Synthesis, characterization and density functional theory study of low cost hydrazone sensitizers. Bull. Chem. Soc. Ethiop. 2015, 29, 137-148.

29. Irfan, A.; Al-Sehemi, A.G.; Chaudhry, A.R.; Muhammad, S. First principles study of the nchannel thiophene based heterocyclic chalcones. Optik 2017, 138, 349-358.

30. Al-Sehemi, A.G.; Irfan, A.; Alrumman, S.A.; Hesham, A.E. Antibacterial activities, DFT and QSAR studies of quizazolinone compounds. Bull. Chem. Soc. Ethiop. 2016, 30, 307316. 